\title{
EXPERIÊNCIA ESTÉTICA E ESCOLA: CARTOGRAFIA DOS ENCONTROS COM A INFÂNCIA E A ARTE NOS ANOS INICIAIS DO ENSINO FUNDAMENTAL
}

\author{
AESTHETIC EXPERIENCE AND SCHOOL: \\ CARTOGRAPHY OF MEETINGS WITH CHILDHOOD AND ART IN THE EARLY \\ YEARS OF ELEMENTARY SCHOOL
}

Fernanda Maria Santos Albuquerque Mestra em Educação, Universidade Federal de Pernambuco - UFPE Caruaru, Pernambuco - Brasil fernanda.m.s.albuquerque@gmail.com

(iD) Conceição Gislâne Nóbrega Lima de Salles Doutora em Educação, Universidade Federal de Pernambuco - UFPE Caruaru, Pernambuco - Brasil cgislane@terra.com.br

\begin{abstract}
Resumo: Este estudo é parte de uma pesquisa mais ampla, que encontrou com a infância, a arte e a experiência estética nos anos iniciais do Ensino Fundamental e convidou-as para uma caminhada, sobretudo com crianças no “espaçotempo" escolar. De modo geral, a pesquisa buscou cartografar os (des)encontros (im)possíveis da infância, da arte e da experiência estética na escola. No entanto, o presente artigo destaca, em específico, os (des)encontros (im)possíveis da experiência estética na escola. Considera a experiência estética como uma relação mais ampla e sensível com o mundo, conforme indicam Guedes e Ferreira (2017), e destaca os desafios postos pela modernidade para que tal relação aconteça, como colocado por Pagni (2014). A pesquisa foi realizada junto a 41 (quarenta e uma) crianças e 06 (seis) professoras de uma escola pública a partir de um plano comum e heterogêneo de produção de dados inspirado na cartografia. Os dados indicam, dentre outras descobertas, a cópia e o silêncio como parte do projeto moderno de redução da experiência estética e destacam as transformações disparadas pelas crianças através da escrita, do desenho e da conversa como (r)existência alternativa ao referido projeto na escola. Desse modo, os (des)encontros (im)possíveis da experiência estética destacados desfalecem todo saber e poder totalitários; a experiência estética parece soprar vida à escola, animar-lhe.
\end{abstract}

Palavras-chave: Arte. Cartografia. Escola. Experiência estética. Infância.

\begin{abstract}
This study is part of a broader research, which found childhood, art and aesthetic experience in the early years of Elementary School and invited them to go for a walk, especially with children in the school "spacetime". In general, the research sought to map the (im)possible (un)meetings of childhood, art and aesthetic experience at school. However, this article specifically highlights the (im)possible (un)meetings of aesthetic experience at school. He considers aesthetic experience as a broader and more sensitive relationship with the world, as indicated by Guedes and Ferreira (2017), and highlights the challenges posed by modernity for such a relationship to happen, as stated by Pedro Pagni (2014). The research was carried out with 41 (forty-one) children and 06 (six) teachers at a public school based on a common and heterogeneous plan for data production inspired by cartography. The data indicate, among other discoveries, copying and silence as part of the modern project to reduce the aesthetic experience and highlights the transformations triggered by children through writing, drawing and conversation as alternative existence to that project at school. In this way, the (un)possible (un)meetings of the aesthetic experience highlighted undermine all totalitarian knowledge and power, the aesthetic experience seems to breathe life into the school, to animate it.
\end{abstract}

Keywords: Art. Cartography. School. Aesthetic experience. Childhood.

\section{Para citar - $(A B N T$ NBR 6023:2018)}

ALBUQUERQUE, Fernanda Maria Santos; SALLES, Conceição Gislâne Nóbrega Lima de. Experiência estética e escola:cartografia dos encontros com a infância e a arte nos anos iniciais do ensino fundamental. . Eccos Revista Cientifica, São Paulo, n. 54, p. 1-22, e16683, jul./set. 2020. Disponível em: https://doi.org/10.5585/eccos.n54.16683. 


\section{Introdução}

A pesquisa na área de educação tem buscado modos de (r)existências alternativas à produção de conhecimento baseada na racionalidade e no tecnicismo estabelecidos com a modernidade. Considerando as mínimas existências, as tantas perspectivas e, sobretudo, dimensões das humanidades - das sensibilidades e experiências estéticas -, temos corroborado com exercícios de pensamento em torno da educação e, em específico, da infância.

Temos partilhado impressões e expressões, rastros da infância, dilacerações de nossas perspectivas, de nossos "espaçostempos". A infância tem se mostrado além das questões cronológicas, "ela é uma condição da experiência” (KOHAN, 2007, p. 86) e, junto às crianças, têm esmaecido as aspirações a sínteses e sintetizações, a essências e matrizes de modo que já não é suficiente falar sobre as mesmas com pressupostos positivistas.

Queremos afetar-nos com a experiência estética que emana delas e, para isso, problematizamos o próprio processo de construção do conhecimento. Atentamos à importância de fazer o que não se costuma fazer, ir aonde não se costuma ir, com quem não se costuma convidar, ver e ouvir pessoalidades mínimas, quase invisíveis, pensar.

O contexto dos anos iniciais do Ensino Fundamental pareceu-nos um "espaçotempo" propício para encontrar e conversar com as crianças, a infância e a experiência estética que aí desponta. Em meio às muitas vivências neste "espaçotempo", consideramos que as vivências em arte, forjadas no dia a dia tanto pelas crianças quanto pelo corpo docente, seriam interessantes aos nossos encontros, pois, assim como a infância, a arte abre passagem à experiência estética, aos possíveis da existência.

Desse modo, refletimos sobre a relação entre infância e arte no contexto dos anos iniciais do Ensino Fundamental a partir, sobretudo, de um "dizer infantil", desde as próprias experiências estéticas das crianças. Diferentemente do modo de pesquisa positivista, que postula a absoluta independência de toda e qualquer experiência particular como condição da produção de conhecimento, consideramos o saber que advém das experiências estéticas.

Buscamos traçar uma relação com o mundo para além da utilidade, alçar modos sensíveis de viver, (re)aproximarmo-nos às coisas do mundo, atentarmos à dimensão sensível, de modo que podemos pensar em uma educação que reflita a experiência estética de que falam Guedes e Ferreira (2017, p. 6): 
[...] aquela que sensibiliza, uma exigência do humano, independentemente do que a arte formalmente reconhecida como arte pode representar para os processos por meio dos quais nos humanizamos. Ela está presente em tudo aquilo que mobiliza nossos sentidos e sentimentos, aquilo que nos emociona, nos toca, nos atravessa, nos faz sabermos vivos.

Assim, ressaltamos que a dimensão estética não se faz presente apenas no ensino de arte na escola. Ela o extrapola, "pois diz respeito à relação mais ampla com o mundo. O outro. A natureza. Mas também, inclui a arte como um dispositivo potente, que permite estabelecer conexões ainda não percebidas" (GUEDES; FERREIRA, 2017, p. 3).

Nesta direção, atiramo-nos no encontro com as crianças com o compromisso de pesquisar com elas. Com inspiração cartográfica, considerando a subversiva transformação do metá-hodos em hodos-metá, não predeterminamos um caminho a partir de metas, mas caminhamos junto às crianças traçando a meta comum de cartografar os (des)encontros (im)possíveis da infância, da experiência estética e da arte na escola.

Aqui destacamos, em específico, os (des)encontros (im)possíveis da experiência estética na escola desta pesquisa, que foi realizada no âmbito da pós-graduação em nível de mestrado, quando caminhamos com um grupo de 41 (quarenta e uma) crianças e 06 (seis) professoras de uma escola pública de rede municipal ao longo do segundo semestre do ano de 2018.

Desse modo, narramos incialmente a nossa caminhada, o plano comum e heterogêneo que traçamos ao caminhar. Na sequência, trazemos os relatos das experiências estéticas que nos afetaram no caminho, onde inspiramo-nos nas transformações provocadas pelas crianças nos "espaçostempos" escolares, nas (im)possibilidades provocadas junto à cópia e ao silêncio dotados de majoritariedade na escola. Tecemos algumas considerações ao fim/(re)início da caminhada.

\section{A caminhada: o traçado do plano comum e heterogêneo}

A pesquisa/caminhada em educação e com crianças não condiz com problematizações verdadeiras ou falsas. Decidimos entregarmo-nos aos mais variados sentidos não classificáveis ou mapeáveis e contamos com a cartografia para registrar nossos movimentos, pois, diferentemente do mapa que representa um todo estático, a cartografia é um desenho que acompanha e se faz ao mesmo tempo que os movimentos de transformação da paisagem (ou dos afetos) (ROLNIK, 2014).

Com inspiração na cartografia, quisemos atenuar o caminho que destoa do modo asséptico de produção científica que marcou a modernidade e a abordagem quantitativa da realidade. Desejamos pesquisar em educação e com crianças de modo séptico, lendo, 
escrevendo e conversando sobre algo que não se extenua em respostas exatas e inquestionáveis. Refletimos que a pesquisa em educação e com crianças se coaduna, pois, com o paradigma qualitativo da pesquisa; este abarca a complexidade do real, seus traços, seus movimentos, seus encontros.

A presença das crianças em nossa pesquisa/caminhada foi acompanhada de cuidados éticos - e estéticos, acrescentamos. Contemplamos a Resolução n ${ }^{\circ}$ 510, de 07 de abril de 2016, assumindo os princípios éticos das pesquisas em Ciências Humanas e Sociais postulados. Atentamos não só ao respeito pela dignidade humana e à proteção devida aos(às) participantes da pesquisa, como nos ocupamos com a passagem de experiências estéticas pela pesquisa/caminhada.

Enfatizamos que as contribuições das pessoas profissionais da educação e as diretrizes legais que partilham a pesquisa/caminhada com as crianças também foram importantes. Junto a estas, quisemos caminhar por entre uma educação que não é só técnica ou prática, mas que é arte e que pode despontar-se com a infância, como preconizou Larrosa (2016). Acreditamos ser possível (re)fazer-se como profissionais da educação, (re)fazer permanentemente a pesquisa/caminhada em educação com crianças e, assim, partimos.

O nosso ponto de partida foi uma escola da rede pública de um município da Mesorregião do Agreste de Pernambuco. O referido espaço tornou-se nosso campo de pesquisa, ou melhor, nosso plano, pois "a intervenção se dá em um plano (o da experiência) e não em um campo" (PASSOS; KASTRUP; ESCÓSSIA, 2015, p. 20). No plano, que é comum e heterogêneo, supera-se o constrangimento moderno à nossa alteridade, o outro deixa de ser simplesmente objeto de projeção de imagens preestabelecidas e pode tornar-se uma presença viva, com a qual construímos nossos territórios de existência (ROLNIK, 2014).

Com instaurações várias que partiram de nós, das professoras, das coisas, dos “espaçostempos" e, sobretudo, das crianças, traçamos um plano caminhando, fomos territórios de passagem para a infância, a arte e as experiências estéticas. Assim, narramos as instaurações várias, todas as intervenções, nosso plano comum e heterogêneo, importando-nos com a partilha e o pertencimento (PASSOS; KASTRUP; TEDESCO, 2016). Segue o caminho traçado.

\subsection{O caminho traçado}

Nosso desejo inicial foi o de atar laços, instaurar uma primeira aproximação, que se deu dia a dia, buscando a continuação do plano comum e heterogêneo, a partilha dos "espaçostempos" da escola. Tal partilha foi acontecendo em momentos com e sem aula, desde 
a rua que passa em frente à escola, ultrapassando o seu portão, passando pela secretaria da escola, pela biblioteca, pela cozinha, até chegar às salas de aula.

Aqui a observação participante foi um instrumento de produção de dados disparado. Com André (2013, p. 100), que retoma o pensamento de Stake (1995), entendemos que a observação inclui elementos materiais como plantas, mapas, desenhos, fotos, bem como elementos imateriais, como o familiar, o econômico, o cultural, o social e o político.

As conversas tornaram-se mais frequentes e destacaram-se como mais uma via possível para a produção de achados. A conversa pode ser assumida como linha de fuga às normativas da pesquisa científica, "como um golpe que desafia a polícia metodológica hegemônica, tão bem representadas por questionários, roteiros, procedimentos rígidos", tal como consideram Ribeiro, Souza e Sampaio (2018, p. 33).

A observação participante e a conversa possibilitaram-nos "estar juntos", ou seja, partilhar a potência do encontro, da capacidade de desenvolver um projeto comum, ou mesmo do desencontro, do descobrimento das mútuas fragilidades (SKLIAR, 2019). Sendo assim, solicitamos e obtivemos as permissões das professoras para acessar as salas de aulas. Inicialmente, passamos um tempo em cada uma das sete salas de aula do período matutino da escola, até que percebemos a importância da permanência em apenas duas salas de aulas: o $2^{\circ}$ Ano A e o $3^{\circ}$ Ano A.

Permanecemos nos "espaçostempos" dessas duas turmas e, com elas, dividimos o ensino e a aprendizagem, as perspectivas adulta e infantil, os "saberesfazeres" docente e discente nas salas de aula e nos demais espaços da escola até que um imprevisto ganhou destaque e provocou outra instauração em nosso plano: uma viagem de estudo para um evento na Universidade do Estado do Rio de Janeiro (UERJ).

A ida ao Rio de Janeiro trouxe instaurações à pesquisa, pois, com um possível afrouxar de laços, pensamos em maneiras de permanecermos presentes na escola, em meio às duas turmas. Dessa forma, foi disparada uma simulação de correspondências com as crianças. Com a criação de materiais e recursos de apoio para o desenvolvimento da atividade, simulamos a escrita de duas cartas às crianças e à professora e propusemos que elas nos respondessem com palavras ou desenhos.

Na primeira carta escrevemos sobre as brincadeiras, as aventuras, a diversão e os estudos que poderiam ocorrer durante a viagem ao Rio de Janeiro e pedimos que as crianças nos

\footnotetext{
${ }^{1}$ Esta expressão é utilizada ao longo de toda a escrita no intuito de evidenciar a imbricação que aí existe, como possibilidade de transgredir as dicotomias herdadas pelo modelo de pesquisa produzido dentro do discurso hegemônico do paradigma moderno, conforme propõe Nilda Alves (FERRAÇO; ALVES, 2018, p. 47).
} 
contassem sobre as (im)possibilidades de aspectos como estes em sua escola. Na segunda carta escrevemos sobre a arte no Rio de Janeiro, sobre suas músicas, suas danças etc., e pedimos que as crianças nos contassem sobre as (im)possibilidades da arte na escola. As imagens abaixo dizem-nos da potência desse deslocamento.

Figura 1 - Correspondências escritas pelas crianças durante a realização da pesquisa, em 2018

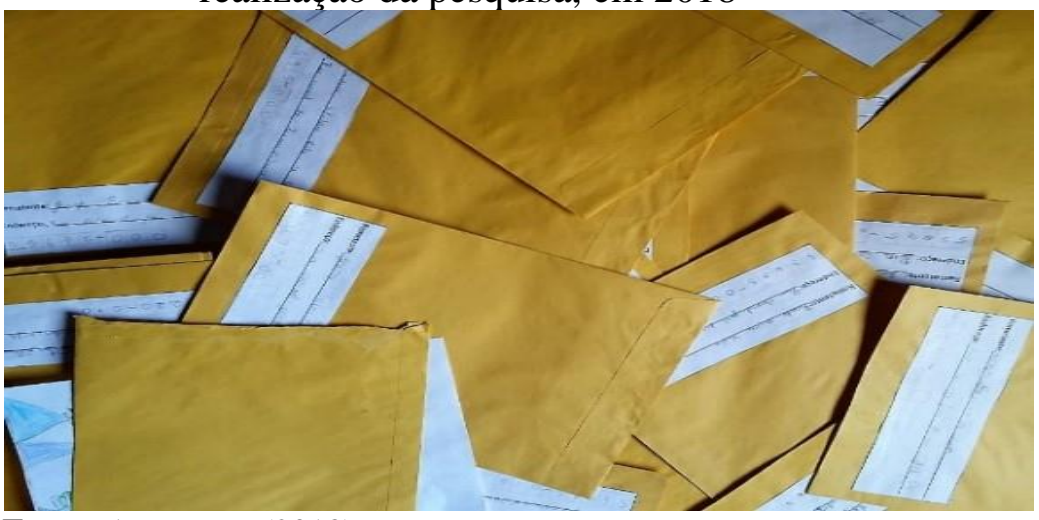

Fonte: As autoras (2018).

As expectativas, o cuidado e a amizade presentes na viagem e nas correspondências formaram um amontoado de afetos - mais alto até que os mais de 300 metros do Morro do Pão de Açúcar no Rio de Janeiro. A escalada pelo amontoado de afetos requereu permutas e mutações, acessamos "espaçostempos" os mais variados em durações de tempo as mais inusitadas.

Destacamos que, afora as cartas acima, outras também foram escritas, estas últimas eram cartas de amor. Aqui, nossos sinceros agradecimentos às crianças que insistiram em subtrair as folhas dos exercícios, que insistem no amor (,) na escola.

Figura 2 - Demais correspondências desviadas pelas crianças durante a realização da pesquisa, em 2018

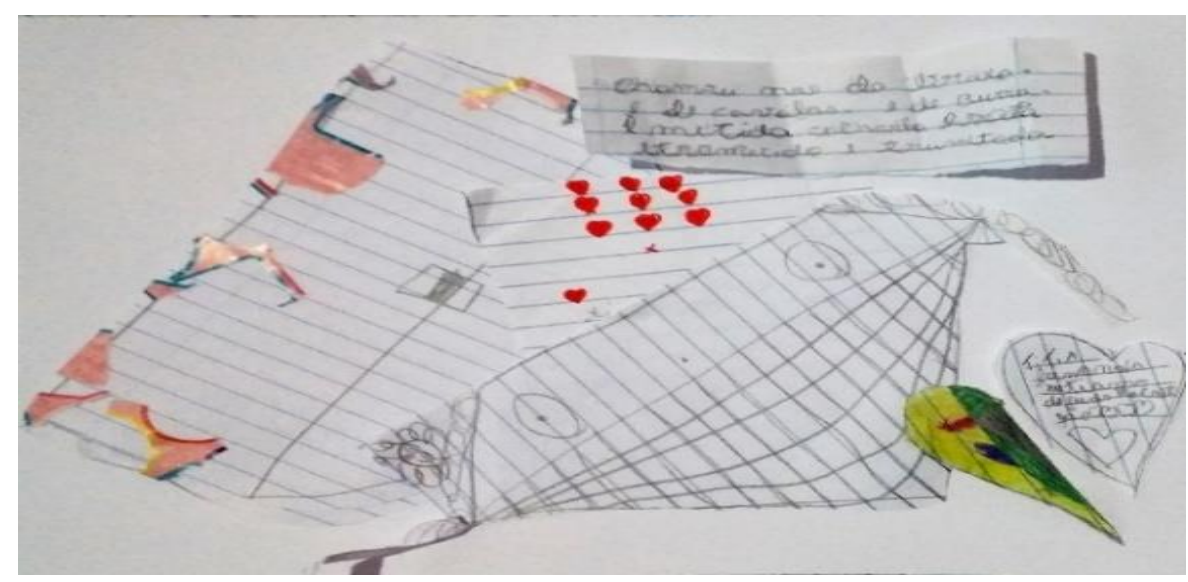

Fonte: As autoras (2018). 
No retorno da viagem, conversamos com as crianças sobre as cartas e a viagem no "espaçotempo" da biblioteca da escola e em um piquenique. Na biblioteca: expectativas; cartas; papéis; músicas; canetas; fitas adesivas; tesoura; confeitos. Além de: imagens do avião, dos museus, das praias das danças, dos teatros e das músicas do Rio de Janeiro. Tudo parecia explodir pelos ares.

No piquenique: pessoas (convidadas ou não); lanches (e merenda) e partilha; riscos (no papel, nas bexigas e nos corpos); conversas (transcritas ou não); brincadeiras (permitidas ou não). Multiplicidade e expansão por fim, como as das bexigas e as da pipoca que esperavam as crianças conosco. As crianças e o reencontro atravessaram-nos, desviaram-nos, fragmentaramnos. Na página seguinte, está disposta a imagem do "espaçotempo" que nos capturou.

E como ocorreu com as correspondências, também ocorreu com o piquenique: as crianças capturaram tais instaurações e lançaram as mesmas sobre nós. Recebemos um convite para um outro piquenique, desta vez, envolto por surpresa e agradecimentos. A imagem deste convite, que também nos capturou, está disposta a seguir.

Figura 3 - O piquenique realizado durante a pesquisa, em 2018

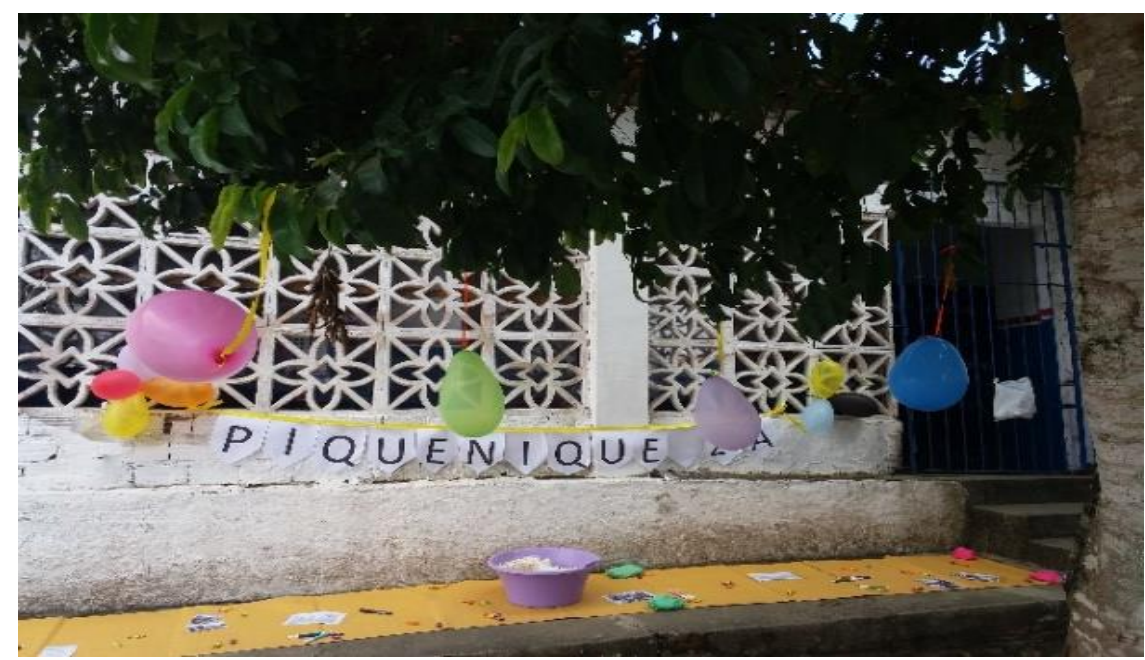

Fonte: As autoras (2018). 
Figura 4 - Convite para um piquenique no desvio realizado durante a pesquisa, em 2018

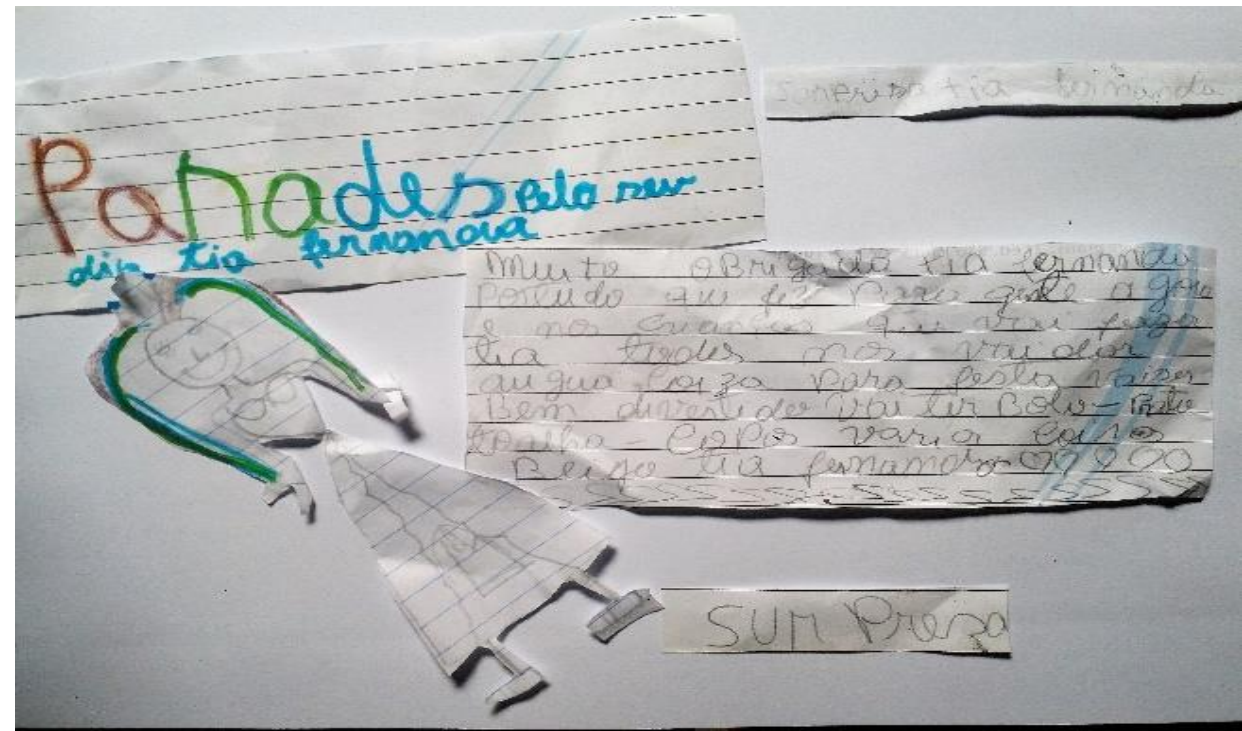

Fonte: As autoras (2018)

Após as instaurações anteriores e muitos momentos ao longo do caminho traçado, quisemos convidar as crianças para mais conversas - essas um tanto mais específicas sobre a pesquisa, mas igualmente "singular e singularizadora, plural e pluralizadora, ativa, mas também pessoal, na qual algo nos aconteça, incerta, que não esteja normatizada por nosso saber, nem por nosso poder, nem por nossa vontade, que nunca saibamos de antemão aonde nos leva" (LARROSA, 2016, p. 72).

Como pano de fundo, fizemos o convite para viver uma aventura em volta de alguns tesouros da escola. Preparamos a biblioteca da escola com tecidos ao chão, sons ambiente, fitas e lápis coloridos, massas de modelar, papéis e um baú com cartões em formato e cores de pedras preciosas, nos quais estavam escritas as palavras: arte; crianças; conhecimento; e experiência. Destacamos que, para além da arte, da infância e da experiência estética (estas últimas tratadas a partir de palavras próximas), o conhecimento apresentou-se para esse momento em virtude da ênfase conteudista da escola.

Com a chegada das crianças à biblioteca, propusemos a escolha de nomes fictícios, embaladas pelo som ambiente relacionado à natureza, à floresta, à aventura, e as crianças concordaram:

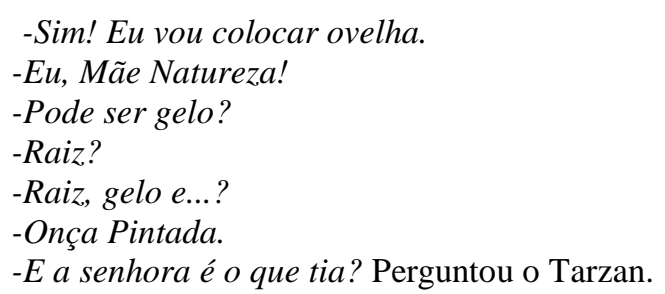


-Brisa. Brisa é aquele vento bem fininho que bate na gente, que é bem gostoso, bem fininho... Relembrei.

-É muito da natureza. Aprovou o Passarinho.

E assim conversamos sobre as referidas dimensões da escola com grupos de quatro crianças, em média, buscando abarcar a diferença intragrupo, a partir da criação de uma associação secreta que guardava os tesouros da escola. Para isso, importava agenciar a passagem de outros sentidos (infantis) dados: à escola, a como ela era; à arte, ao que ela significava para as crianças, à sua importância na escola; às crianças, aos seus modos de existência e às suas (im)possibilidades na escola; ao conhecimento, ao ensino e aprendizagem na escola; à experiência, aos acontecimentos na escola e seus desdobramentos; e a tudo mais que as crianças quiseram contar e/ou perguntar.

Ao fim das conversas, as crianças criaram mapas que indicavam onde/quando podemos esconder/encontrar os tesouros sobre os quais conversamos. Posteriormente, todos os mapas criados foram expostos na escola e, por indicação das crianças, houve tesouros de verdade a serem procurados nos locais indicados pelas mesmas - uma instalação. Por meio de uma instalação, buscamos aproximarmo-nos da arte contemporânea, uma vez que essa, assim como a infância e a experiência estética, pode ser a irrupção de acontecimentos (LOPONTE, 2008).

Com isso, a escola foi “[...] algo como um território de passagem, algo como uma superfície sensível que aquilo que acontece afeta de algum modo, produz alguns afetos, inscreve algumas marcas, deixa alguns vestígios, alguns efeitos”, foi “[...] sobretudo um espaço onde têm lugar os acontecimentos" (BONDÍA, 2002, p. 24).

Figura 5 - A instalação realizada durante a pesquisa, em 2018

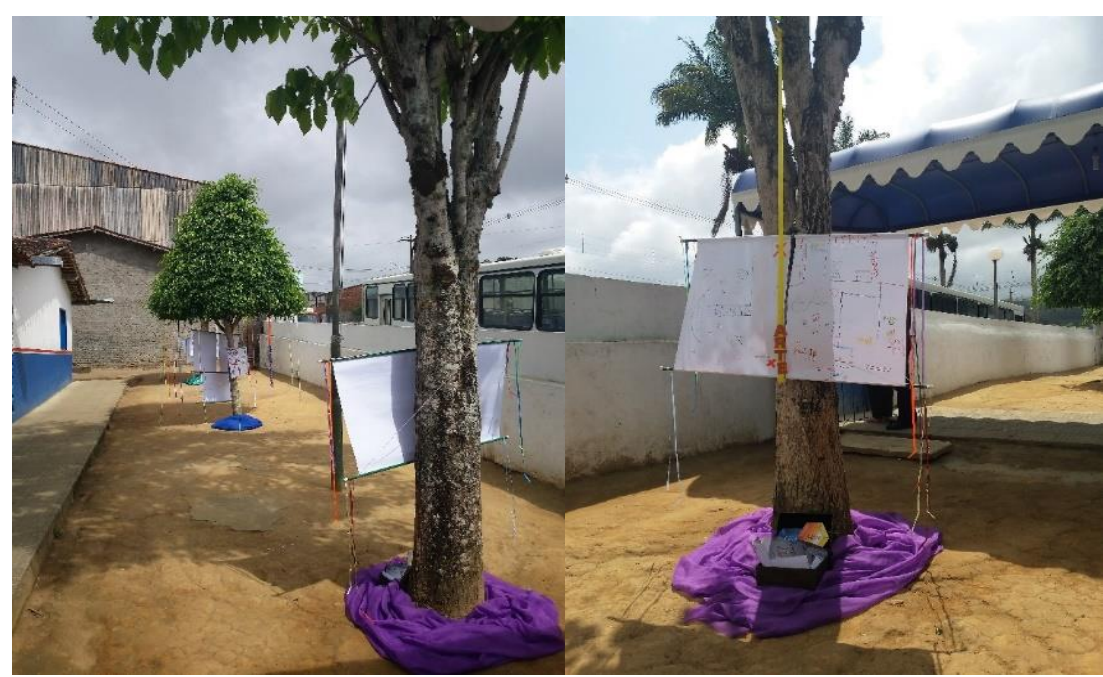

Fonte: As autoras (2018). 
Figura 6 - Os mapas dos tesouros construídos pelas crianças durante a realização da pesquisa, em 2018

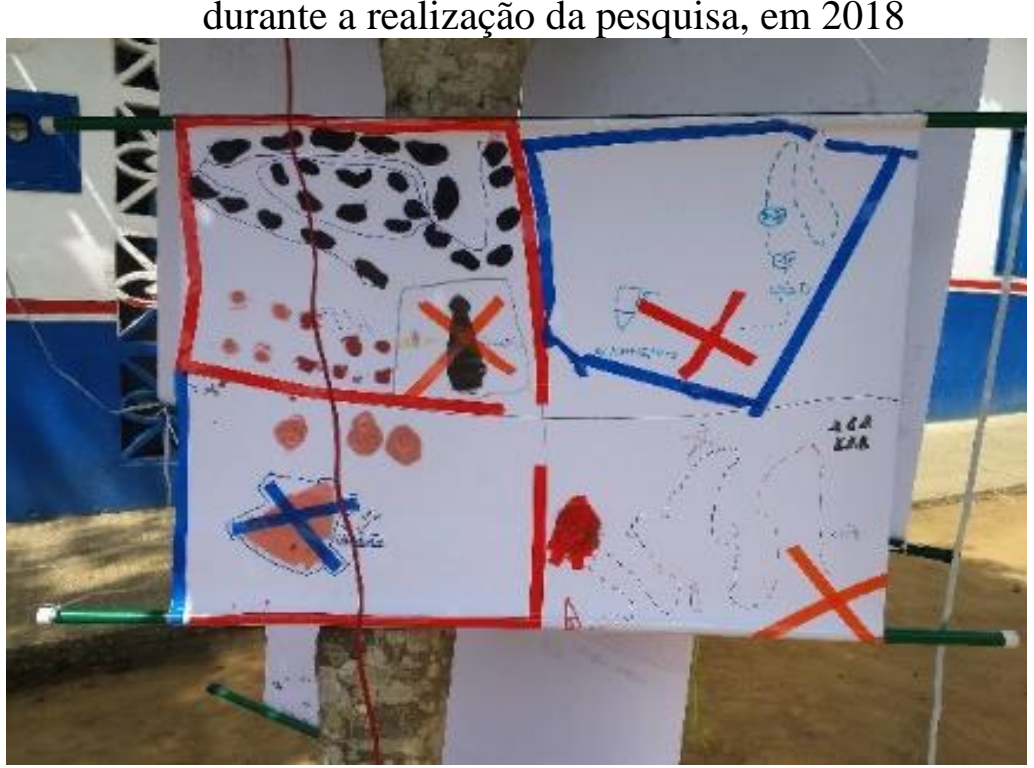

Fonte: As autoras (2018).

Por fim, destacamos as conversas que tivemos com as professoras: duas estando nas salas de aula, outras duas na coordenação e direção da escola, e mais duas na coordenação pedagógica da Secretaria de Educação do município, mas, como foi enfatizado pelas mesmas, todas professoras (e flores, acrescentamos).

As conversas iniciaram com a escolha de nomes fictícios para as professoras: brotaram o Jasmim, a Margarida, a Violeta, a Hortênsia, a Rosa e a Rosa Amarela. E seguiu com a abertura de envelopes coloridos com títulos e perguntas disparadoras, que envolviam as experiências estéticas das crianças no entremeio da arte e da infância no contexto dos anos iniciais do Ensino Fundamental.

Figura 7 - Envelopes para mais conversa(s) com as professoras durante a realização da pesquisa, em 2018

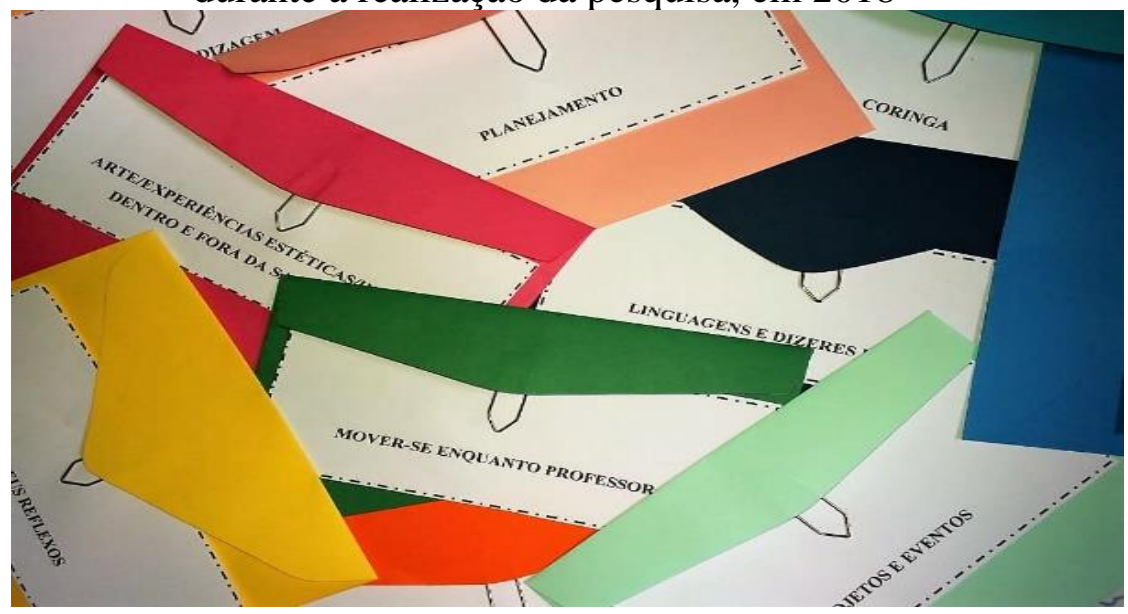

Fonte: As autoras (2018). 
Ao longo do caminho, não quisemos revelar ou desvelar uma única relação entre infância, experiência estética e arte nos anos iniciais do Ensino Fundamental que viesse a sobrepor às demais relações já compreendidas. Para tal, assumimos "olhos dadivosos" que não exercem domínio sobre o existente e, por isso, encontram um mundo em plenitude, em independência, em inacessibilidade e mistério (LARROSA, 2006, p. 111). São apresentadas, a seguir, as reflexões sobre o ânimo do caminho percorrido, os (des)encontros (im)possíveis por entre e em meio à experiência estética junto às crianças/seres diversos e professoras/flores na/da escola.

\section{No caminho: ânimo ou da experiência estética que sopra vida à escola}

Experiência é experimento, tipo aqueles experimentos de ciências, tipo aqueles cientistas que derruba lá aquele negócio nos copinhos... Apressou-se o Tarzan.

Eu amo experiência tia, de química, de ciências! Porque você faz novas experiências, você coloca um hidrocor na água, vai dá azul, é legal! Eu gosto! Acrescentou o Sabiá.

$\mathrm{O}$ termo experiência, em um primeiro momento, remeteu as crianças aos experimentos científicos predominantes na modernidade. Os experimentos parecem ter sido a experiência por excelência desde a modernidade, quando a razão foi sobreposta às demais dimensões da existência, desapropriando o caráter inefável da experiência. Dessa forma, a descrição moderna da experiência parece reduzir a mesma ao experimento, no entanto, a experiência pode preceder os experimentos positivistas da modernidade - podendo, até mesmo, neles irromper - e acontecer em “espaçostempos” vários, como na escola.

$\mathrm{O}$ interessante é que, embora as ações da experiência estejam em baixa desde a modernidade, como apontou Benjamin (1987), o Sabiá e o Tarzan pareciam buscar a inefabilidade da experiência no que há de indescritível em um experimento, a euforia da transformação, o surpreendente.

Apesar disto, são nítidos alguns reflexos da baixa da experiência, em específico, na escola. Neste "espaçotempo", há, muitas vezes, a formalização do aprendizado e a restrição do ensino a uma tecnologia, "elaborando-os teoricamente sob a ótica de uma racionalidade que exclui aquilo que provém do sensível, do inefável, enfim, da experiência, rompendo aí os laços dos saberes e práticas escolares com a vida, embora a redimensione como vida nua" (PAGNI, 2014, p. 12).

Aqui, juntamo-nos ao Sabiá e ao Tarzan para afirmar que a experiência pode ser a alma da escola. Ela traz a vida à mesma, faz tremer, rir da precisão que pretendemos neste 
“espaçotempo". Ela parece impedir-nos de manipular a escola, mostrando-nos que há "algo além" do capturável, da síntese da escola a atos mecânicos de...

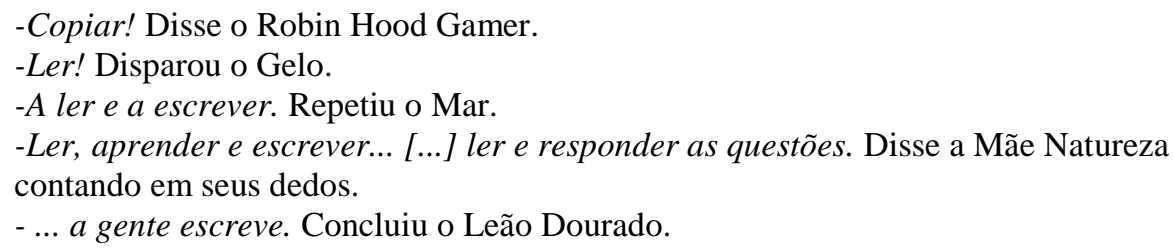

A experiência sopra suas dimensões à escola, sopra exterioridade, alteridade e alienação; subjetividade e transformação; passagem e paixão (LARROSA, 2011). Ela invade a escrita e a leitura, devotando-lhes sentido, fazendo-as valer a pena. Assim, a leitura torna-se "uma prática relacionada à ficção, à invenção, à narração. E “escrever” não poderia ser outra coisa que o eco primeiro da leitura" (SKLIAR, 2019, p. 92).

Aqui, enfatizando os transbordamentos na/da escola, as transformações e modos de (r)existência provocados pelas crianças, que imbuem de experiência estética os processos de ensino e aprendizagem, sobretudo a enfática apropriação dos sistemas de escrita alfabética e dos números decimais indo arábicos (e da cópia que é colocada como inerente a estas) e o insistente silêncio que se pretende na escola.

As crianças provocam acontecimentos. As suas experiências estéticas trazem vida aos modos de produção de conhecimentos na escola, transformam a si, às demais pessoas, à educação e à própria escola. Elas somam forças à evocação da sensibilidade à educação feita por Araújo (2009), em uma atitude de não-resistência aos desafios do devir, de superação de posturas defensivas, pois, a educação é uma ação teórico-vivencial que implica a fruição da sensibilidade, um rito vivo de iniciação aos saberes e sentires (ARAÚJO, 2009, p. 199), mesmo quando se remetem ao ensino e aprendizagem em língua portuguesa e em matemática.

As crianças corroboram a valorização da educação que apresenta Arendt (2000), propondo que a educação possibilite novos mundos, burlando as correntes intervenções ditatoriais adultocêntricas. São elas que, em sua maioria, propõem/reivindicam a partilha do mundo, a possibilidade de novos mundos nos mais variados "espaçostempos", inclusive na escola. Elas também promovem a suspensão; a profanação; a atenção e o mundo; a tecnologia; a igualdade; o amor; a preparação; e a responsabilidade pedagógica na escola de que falam Masschelein e Simons (2014). As crianças forjam, continuamente, "espaçostempos" outros. Nos pontos seguintes escrevemos acerca das transformações no "espaçotempo" escolar junto às crianças. 


\subsection{Da cópia à escrita e ao desenho enquanto experiência estética}

A apropriação do sistema de escrita alfabética, bem como a apropriação do sistema numérico decimal indo arábico e suas operações, ambas colocadas pelas crianças como difíceis, são animadas e transformadas pelas experiências estéticas disparadas por elas na escola. De respostas calculáveis e exatas requeridas pelo sistema numérico adotado, passa-se ao desenho e a muito mais, por exemplo, como aconteceu quando

Era aula de matemática e usávamos o livro didático. Nesse momento, a Mãe Natureza deixou suas sandálias embaixo da mesa e, com os pés descalços, veio mostrar as maçãs que pintou na atividade de matemática. Mais que acerto ou erro, A Mãe Natureza buscava experiências (não só nas maçãs pintadas, mas também em seus pés no chão e na partilha de suas maçãs) (DIÁRIO DE CAMPO, 2018).

Bem como, de cópias, sobremaneira presentes nos processos de apropriação do sistema de escrita alfabética, passa-se à escrita e ao desenho em: (1) correspondências de viagem; (2) cartas de amor; e (3) convites para celebrações diversas.

A ênfase na cópia parece ser o resumo do resumo da escola feito pelas crianças, desde o suspiro uníssono que ecoa após os anúncios de tarefas no quadro branco, passando pelos apelos de limite de questões ou textos escritos, até a relação (direta) entre a intensidade da cópia e o comportamento das crianças na sala de aula. Nesse sentido, conversamos:

\footnotetext{
-Mas dentro da sala, quando é pra, quando a tia não chega, a gente brinca de esconde-esconde... destacou a Ovelha. Então conversávamos sobre o que acontecia quando a professora chegava e a Ovelha contou-nos: -Aí a gente brinca um pouquinho, que ela deixa! E acrescentou: se a gente fizer barulho, aí ela arenga, ela bota a gente pra sentar...

-E bota bem muita tarefa no quadro! Contribui a Mãe Natureza.

-[...] Teve uma vez que ela foi até o sétimo! Acrescentou a Coruja.
}

Em outro momento, também conversamos sobre algumas experiências da Água em outra escola: nas suas palavras, uma escola que, no $1^{\circ}$ Ano, só fazia até o segundo (quesito) e, no $5^{\circ}$ Ano, fazia até o quarto ou até o nono (quesito). A sugestão é de que há uma relação direta entre a extensão da cópia não só com o mau comportamento, como também com a faixa etária das crianças. Quanto maior for o mau comportamento e a faixa etária das crianças, maior parece ser a cópia na escola. A cópia tem se caracterizado como a maneira mais eficaz de fazer calar as crianças e a infância na/da/e a escola.

No entanto, as crianças transformam a cópia na escrita e no desenho. Elas instauram intensidades, escapando da cronologia dos anos escolares, das faixas etárias. Aproximam-se do que Skliar chama de escrever, escrevendo: 
Escrever com a língua que se escuta, não com a que já se falou.

Quer dizer, escrever calando a própria língua.

Porque a escrita da língua que já se falou - essa que os soberbos creem ser própria e apropriada - está infectada pela névoa e pelas falsas acusações, é voraz e morde, não acaricia: mostra repetidas vezes suas garras (SKLIAR, 2019, p. 115).

Escrever vendo pela primeira vez, ou mesmo, desenhando - desenhos que, como a linguagem (SKLIAR, 2019), têm uma porção de certeza e o resto de incerteza. Escrita e desenho que resistem junto à infância e à escola, fazendo-as resistir. Leitura que nos "desterritorializam". Correspondências que nos dão acesso a outros "espaçostempos".

Figura 8 - Correspondências das crianças abertas durante a realização da pesquisa, em 2018

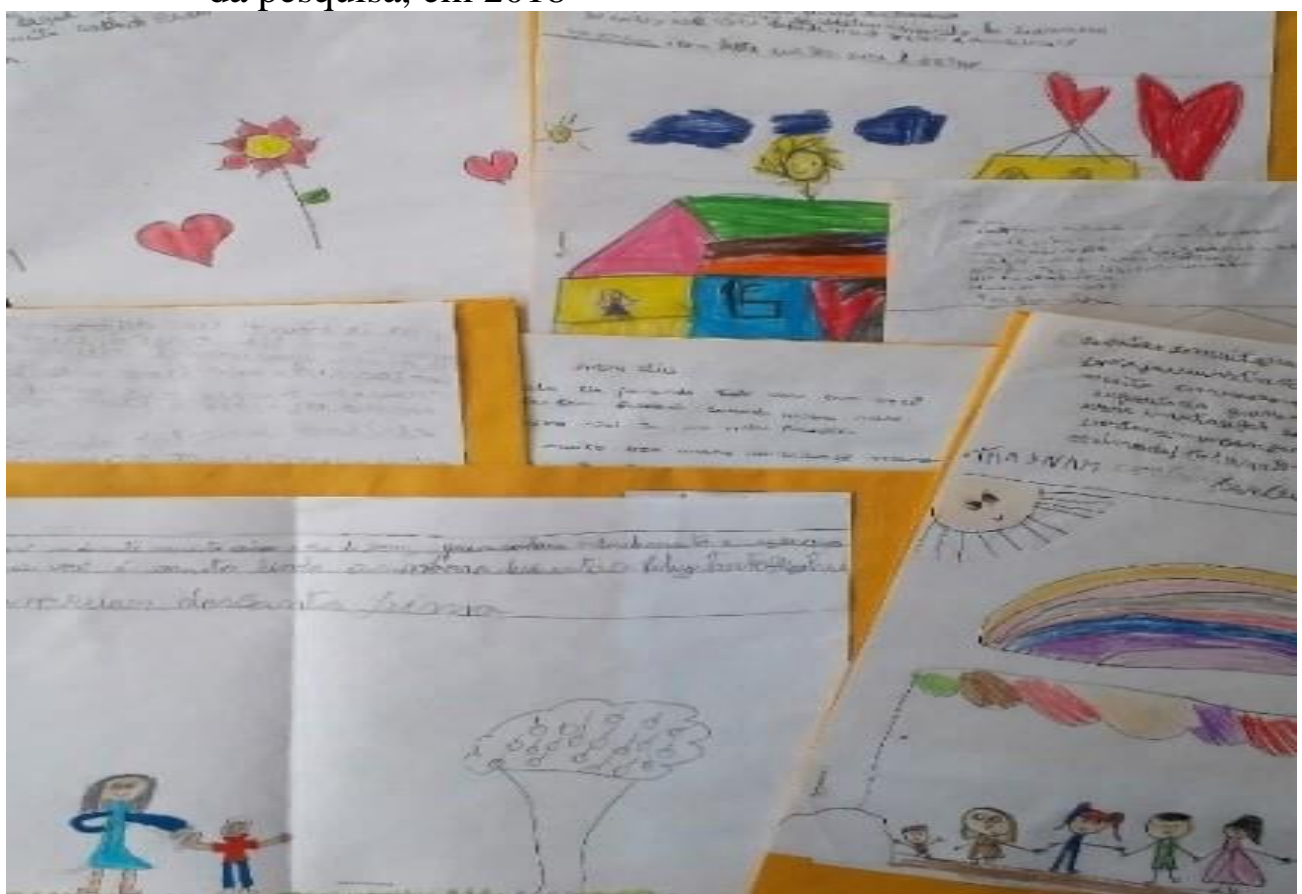

Fonte: As autoras (2018).

No caso das (1) correspondências durante a viagem de estudos que fizemos ao Rio de Janeiro, foram escritas a saudade e a segmentaridade do desejo em votos de boa viagem e a expectativa pelo retorno.

[...] eugostaria quevoseesteveseaquicoagemte [...] euestomemosconsaudade! « Escreveu a Sereia.

Eu espero ger você votilo-

Go mais eu acho ger você estar didivitir i te ver. Escreveu o Lobo Alfa.

Eu estou com muita Saudade não vejo a Hora de a Senhora chega para eu lhe abraça bem muito e nunca lhe soltar com tanta Saudade que Eu Estou aqui se Eu Estivesse Dinheiro Eu comprava uma passagem para ir para o Rio De Janeiro ficar com a Senhora. Beijos, Xau $\vee$ ! Volte logo. Escreveu o Mar. ${ }^{2}$

\footnotetext{
${ }^{2}$ A transcrição da escrita das cartas das crianças foi feita literalmente, respeitando-se as carícias presentes nas mesmas.
} 
A viagem, para quem vai e para quem fica, é mesmo segmentaridade, composição de muitos fluxos que se atravessam ao mesmo tempo, é devir (GAIVOTA, 2017). Quem fica pode viajar através de quem vai à viagem, pois “ $\mathrm{O}$ viajante traz consigo a vertigem, o estranhamento, o outro" (GAIVOTA, 2017). A ansiedade pelo retorno corrobora a afirmação de que: "Não viajamos por nós, mas pelo mundo. É ao viajar que podemos fazer viajar, é ao nos abrir que podemos fazer abrir (o mundo) e é ao fugir que podemos fazer fugir (ou voar)" (GAIVOTA, 2017, p. 68). Uma relação dotada de cuidado e alteridade que parece deixar pouco "espaçotempo" para desenhar e escrever sobre ser criança e sobre a arte na escola, como pedimos às crianças por carta:

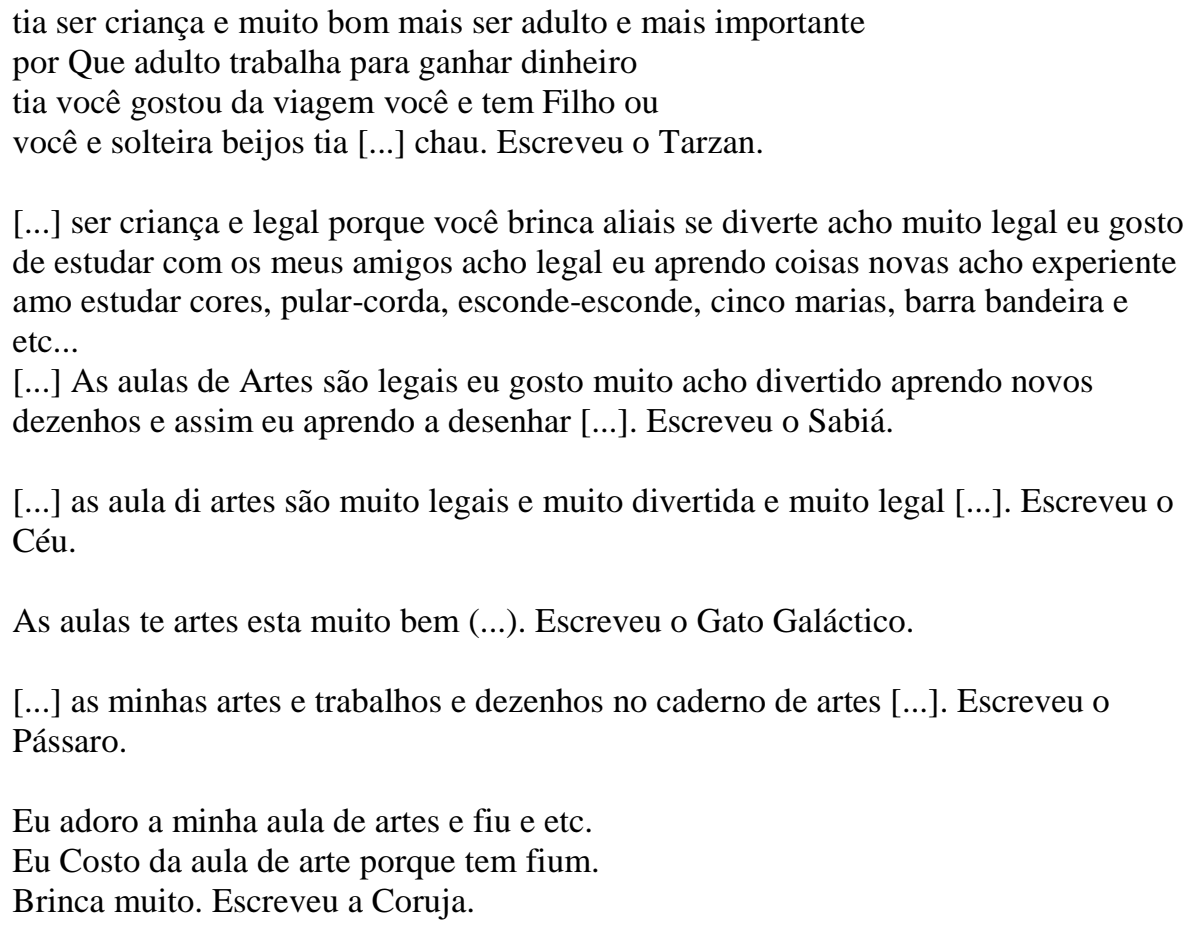

Destarte o pouco "espaçotempo", as provocações foram abundantes. Inicialmente, sobre ser criança, provocou-nos a escrita do Tarzan, que relacionou a importância das crianças e dos adultos com o consumo. Corroboramos o Tarzan acrescentando as considerações de Rodrigues e Roble (2015) de que, para além das relações entre as pessoas, a própria relação consigo parece ser fundamentada no consumo desde a modernidade, quando se passou a poupar o ver, o "espaçotempo", o olfato, o paladar, a audição, o tato, enfim, os sentidos, as sensações, a capacidade de sentir, de saber-se vivo.

Ainda sobre ser criança, conforta-nos o reconhecimento do Sabiá da importância de ser criança baseada no brincar, na diversão e na sensação "experiente" de aprender coisas novas resistência diante do imperativo do consumo que concorre para a destituição da importância da 
infância. Já sobre (as aulas de) arte... os desenhos parecem ser o seu resumo. Boa, legal e divertida parecem adjetivos um tanto genéricos. Dessa forma, sobre (as aulas de) arte, conversamos em outros momentos posteriores.

Ainda sobre as correspondências de viagem, não poderíamos desconsiderar a presença de quantidades de linhas (em papéis em branco) marcadas por " $\mathrm{x}$ " e campos para assinalar respostas (também com “x”). Tal presença faz-nos considerar a ameaça de sucateamento do que poderíamos considerar uma máquina de guerra, pois, o exercício de escrita enquanto experiência estética faz do pensamento uma potência nômade, abala o modelo do aparelho de Estado, como o faz a máquina de guerra (DELEUZE; PARNET, 1998), no entanto, por vezes, tal escrita é ameaçada pelo retorno à cópia, conforme a imagem a seguir.

Figura 9 - O retorno à cópia presente nas correspondências das crianças, escritas durante a realização da pesquisa, em 2018

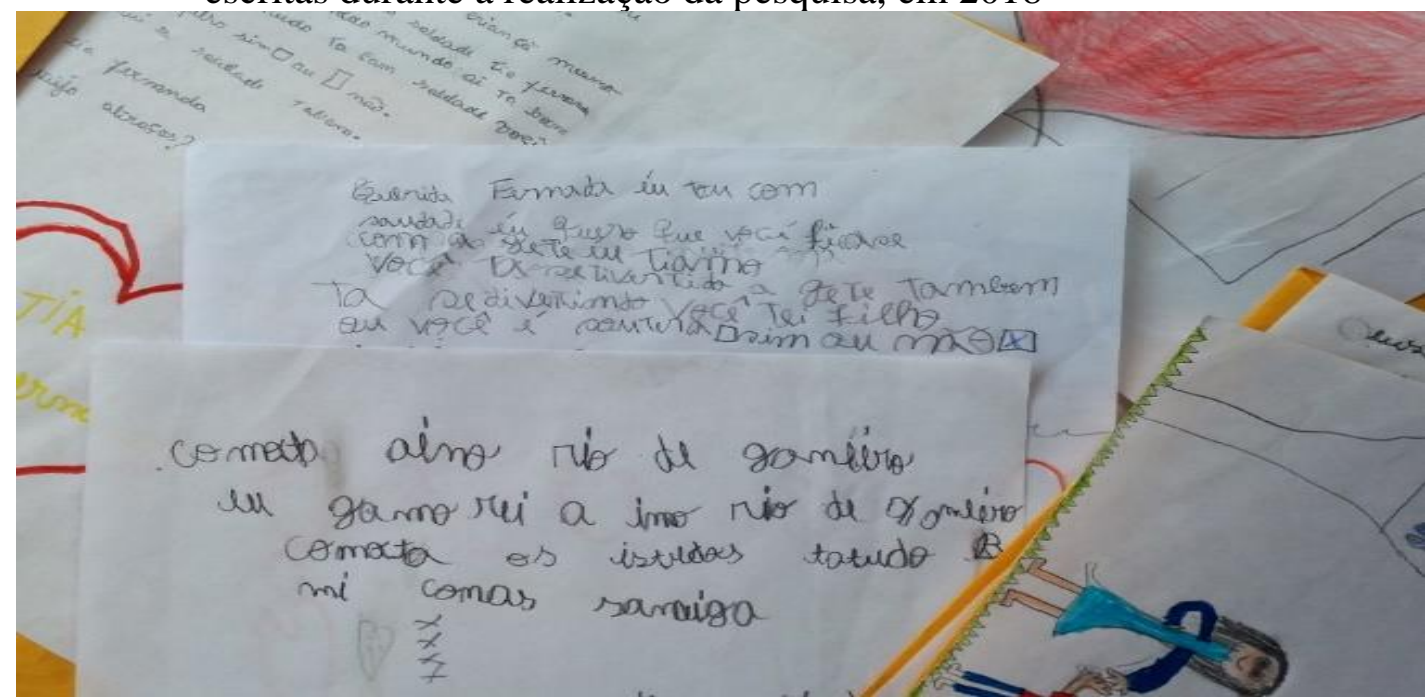

Fonte: As autoras (2018).

Os " $\mathrm{x}$ " riscados a lápis e à caneta - este último por nós - diz-nos de uma possível tentativa de apropriação da máquina de guerra pelo Estado, voltando-a contra os nômades e aproximando-a ao aparelho de Estado - uma espécie de agenciamento concreto que efetua a máquina de sobrecodificação de uma sociedade (DELEUZE; PARNET, 1998).

Os "x" parecem partilhar com o aparelho de Estado sua organização dos enunciados dominantes e da ordem estabelecida de uma sociedade, das línguas e dos saberes dominantes, das ações e dos sentimentos, conformes os segmentos que prevalecem sobre os outros, assegurando a homogeneização dos diferentes segmentos, sua convertibilidade, sua “traduzibilidade" (DELEUZE; PARNET, 1998).

No entanto, sempre haverá uma tensão entre o aparelho de Estado e a máquina de guerra, em seu empreendimento de destruir o Estado, os súditos do Estado, e até mesmo de se destruir 
ou de se dissolver ao longo da linha de fuga (DELEUZE; PARNET, 1998). Assim a escrita enquanto experiência segue operando, dessa vez, através de (2) cartas de amor - não correspondidas em curto prazo, assumimos -, fazendo-nos pensar no porquê do descaso com as cartas de amor das crianças na escola.

Ti eu te amo. Declarou a Água.

[...] Tia eu quero dizer qui todo mundo tiama

Tia quero dizer qui assenhora vai brinca com a gente no reqreio. Declarou a Fênix.

As cartas de amor das crianças parecem representar cartas e amores menores, como a literatura menor de que falam Deleuze e Guattari (2017). Aproximamos as cartas de amor das crianças das características de uma literatura menor à medida que consideramos: o pertencimento dessas a uma espécie de língua que uma minoria constrói numa língua maior, uma língua de afetos que as crianças constroem numa língua de técnicas e habilidades da educação escolar; a escrita política das cartas de amor, uma vez que requer experiências estéticas na escola; e o valor coletivo que têm as cartas de amor (individuais a princípio).

Quanto aos (3) convites...

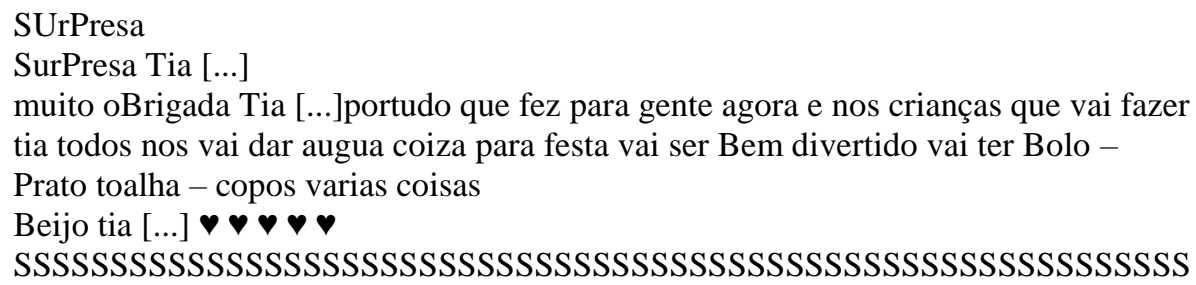

Eles inserem surpresas na rotina da escola, requerem esforços, interrompem as atividades rotineiras, dão "espaçostempos" para a celebração de algo a mais que letras e números, possibilitam, mais uma vez, a experiência estética na escola, uma vez que

\begin{abstract}
A experiência, a possibilidade de que algo nos aconteça ou nos toque, requer um gesto de interrupção, um gesto que é quase impossível nos tempos que correm: requer parar para pensar, parar para olhar, parar para escutar, pensar mais devagar, olhar mais devagar, e escutar mais devagar; parar para sentir, sentir mais devagar, demorar-se nos detalhes, suspender a opinião, suspender o juízo, suspender a vontade, suspender o automatismo da ação, cultivar a atenção e a delicadeza, abrir os olhos e os ouvidos, falar sobre o que nos acontece, aprender a lentidão, escutar aos outros, cultivar a arte do encontro, calar muito, ter paciência e dar-se tempo e espaço (LARROSA, 2016, p. 25).
\end{abstract}

Finalizamos esse ponto considerando que o desenho e a escrita como experiência estética traçam um rastro, vibram no ar, tocam a outros (LARROSA, 2016, p. 113); e fazem isso na escola, mas não sem esforço. Passemos agora às outras transformações. 


\title{
3.2 Do silêncio sepulcral à conversa que anima
}

Junto à cópia, que foi colocada pelas crianças, está a ênfase da escola no silêncio, na exigência de um silêncio sepulcral - em uma espécie de didática do comportamento - ao qual a experiência estética anima e leva à conversa - uma espécie de didática da invenção...

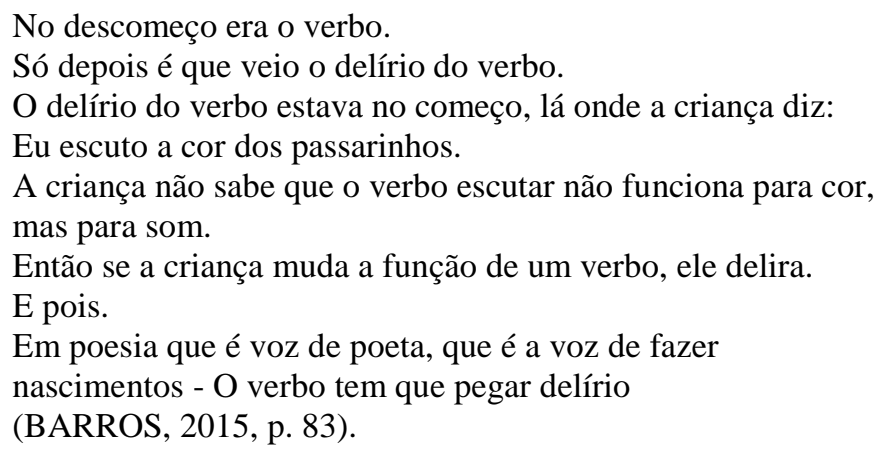

A didática da invenção proposta por Manoel de Barros contém vinte e uma estrofes, dentre as quais destacamos alguns versos acima. Inventar não é mesmo algo fácil de aprender, é mais fácil desinventar, desaprender... "desaprender 8 horas por dia ensina os princípios", como escreveu o poeta na primeira parte da didática.

Como na didática da invenção, consideramos que "as coisas que não têm nome são mais pronunciadas por crianças" e, desde que as perguntas e pensamentos sejam fabricados e colocados por si com elementos vindos de toda parte sem objeções, haverá muito o que dizer (DELEUZE; PARNET, 1998), até mesmo durante a aplicação de provas na escola:

\begin{abstract}
Era o início das avaliações objetivas e a primeira prova foi a de português. Antes da prova, as crianças brincavam - a professora falou que estava deixando eles aquecerem e, só após ver o modo como a avaliação aconteceu, entendemos o porquê desse momento ser considerado um aquecimento. Diferente do que se costuma esperar em avaliações objetivas, ou seja, silêncio sepulcral, corpos distantes e com movimentos restritos, as crianças conversavam sobre tudo, menos respostas da prova, e inventavam: a brincadeira para o recreio (polícia e ladrão, talvez); cantos; imitação de sons de animais (besouros); danças nas cadeiras; pinturas e desenhos; empréstimo de lápis comum e de lápis de cor; proposições de que a avaliação de português também vale nota de arte... a professora cuidava da leitura da prova; reforçava que não se pode falar a resposta das questões da prova, apenas copiar...
\end{abstract}

Havia muito o que dizer, mas não a responder. As respostas para a prova não pareciam tão importantes quanto o recreio, o porvir; as expressões (corporais ou não); as partilhas; as invenções. As crianças não se demoravam nas respostas, mas nas conversas sim. As conversas perduram até mesmo durante provas, porque não se tem tema específico, apropriado ou não.

Com Skliar (2019, p. 84), consideramos que conversar aproxima-se a "batalhar contra a indiferença, de não se submeter docilmente a essa ideia de comunicação que hoje parece ser 
mais uma arma de guerra ou uma propriedade das empresas de celulares ou um falso sorriso para a venda de eletrodomésticos" - expressões da modernidade.

Conforme aponta Pagni (2014), o projeto da modernidade reduz a experiência ao empírico, e na continuação, há a desqualificação da experiência como um saber, a restrição do pensamento ao conhecimento científico e à tecnologia. Pagni (2014) faz-nos refletir que tal esvaziamento do sentido da experiência concorreu para o silenciamento do indivíduo e para um esvaziamento existencial sem precedente, trazendo consequências para a educação.

As transformações aqui descritas parecem ser resistência a esta lógica mais técnica na escola. Ao mover a apropriação dos sistemas de escrita alfabética e numérico decimal indo arábico, bem como ao animar com conversas os "espaçostempos" da escola, as crianças reforçam a arte que há na educação, a dimensão estética e a implicação com a vida que permeiam as experiências dentro e fora das salas de aula.

\section{Considerações finais}

A pesquisa em educação produz conhecimento de maneiras alternativas às baseadas na racionalidade e no tecnicismo. Uma dessas maneiras é baseada nos saberes advindos da experiência estética, dos atravessamentos e deslocamentos que sofrem aquele, aquela e aquilo que se tornam passagem para ela.

A realização de uma pesquisa com crianças nos anos iniciais do Ensino Fundamental, considerando os modos como a relação entre a infância e a arte abrem passagem para a experiência estética na escola, possibilitou-nos partilhar modos de existência além e, por vezes, aquém, da utilidade, modos nem sempre adequados, nem sempre quistos, nem sempre controláveis, nem sempre cultivados, nem sempre amistosos, mas, sempre, bonitos de se ver, de se sentir.

A partir das crianças, inquietamo-nos com os (des)encontros (im)possíveis da infância, da experiência estética e da arte na escola e destacamos aqui os (des)encontros (im)possíveis da experiência estética cartografados na escola. Consideramos suas instaurações a partir de mínimas interrupções e irrupções, salientando que a infância faz-se "condição da experiência" (KOHAN, 2007) na escola.

Desse modo, destacamos a resistência ao caráter inefável na educação escolar. Tal resistência parece reduzir a experiência ao experimento, o ensino e a aprendizagem à apropriação dos sistemas numérico e de escrita alfabética, a escola a atos mecânicos de cópia em silêncio. No entanto, há insistências. 
A experiência estética, nada obstante, anima a escola, faz a mesmo pulsar. O sopro parece ser dado, sobretudo, pelas crianças. Elas identificam os eixos imobilizantes da escola, como a cópia e o silêncio, e mobilizam experiências estéticas a partir dos mesmos. De respostas calculáveis e exatas, passa-se a desenhos, imaginação, experiência. De cópias penosas, passase a correspondências, cartas de amor e convites. Do silêncio sepulcral passa-se a conversas indeterminadas.

Na pesquisa em educação, na produção de conhecimento na escola, são mobilizados relações e processos de ensino e aprendizagem intensos, envolvidos pela experiência estética, envolvendo-se com esta e envolvendo-nos. Assim, a escola (r)existe.

\section{Referências}

ANDRÉ, Marli Elisa Damalzo Alfonso de. O que é um estudo de caso qualitativo em educação? Revista da FAEEBA - Educação e Contemporaneidade, v. 22, n. 40, p. 95-103, jul./dez. 2013. doi: http://dx.doi.org/10.21879/faeeba2358-0194.2013.v22.n40.p95-103. Disponível em: https://www.revistas.uneb.br/index.php/faeeba/article/view/753. Acesso em: 14 maio 2018.

ARAÚJO, Miguel Almir Lima de. Os sentidos da sensibilidade e sua fruição no fenômeno do educar. Educação em Revista, Belo Horizonte, v. 25, n. 02, p. 199-222, ago. 2009. doi: https://doi.org/10.1590/S0102-46982009000200009. Disponível em: https://www.scielo.br/scielo.php?script=sci_arttext\&pid=S0102$46982009000200009 \& \operatorname{lng}=$ pt\&tlng=pt. Acesso em: 06 jul. 2020.

ARENDT, Hannah. Entre o passado e o futuro. Trad. Mauro W. B. de Almeida. 5. ed. São Paulo: Perspectiva, 2000.

BARROS, Manoel de. Meu quintal é maior do que o mundo. Rio de Janeiro: Objetiva, 2015.

BENJAMIN, Walter. Magia e técnica, arte e política. Ensaios sobre literatura e história da cultura. Obras Escolhidas. v. 1. Tradução Sérgio Paulo Rouanet. São Paulo: Brasiliense, 1987.

BONDÍA, Jorge Larrosa. Notas sobre a experiência e o saber de experiência. Tradução de João Wanderley Geraldi. Revista Brasileira de Educação. Jan/Fev/Mar/Abr, n. 19, 2002, p. 04-27. doi: https://doi.org/10.1590/S1413-24782002000100003 Disponível em: http://www.scielo.br/pdf/rbedu/n19/n19a02.pdf> Acesso em: 13 dez. 2016.

BRASIL. Resolução $n^{\circ} 510$, de 07 de abril de 2016. Dispõe sobre as normas aplicáveis a pesquisas em Ciências Humanas e Sociais cujos procedimentos metodológicos envolvam a utilização de dados diretamente obtidos com os participantes ou de informações identificáveis ou que possam acarretar riscos maiores do que os existentes na vida cotidiana, na forma definida nesta Resolução. Seção 1, p. 44-46. Disponível em:

http://conselho.saude.gov.br/resolucoes/2016/reso510.pdf Acesso em: 18 jun. 2018. 
DELEUZE, Gilles; GUATTARI, Félix. Kafka: por uma literatura menor. Tradução Cíntia Vieira da Silva. Belo Horizonte: Autêntica, 2017.

DELEUZE, Gilles; PARNET, Claire. Diálogos. Tradução Eloisa Araújo Ribeiro. São Paulo: Escuta, 1998.

FERRAÇO, Carlos Eduardo; ALVES, Nilda. Conversas em redes e pesquisas com os cotidianos. In: RIBEIRO, Tiago; SOUZA, Rafael de; SAMPAIO, Carmen Sanches (org.). Conversas como metodologia de pesquisa: por que não? Rio de Janeiro: Ayvu, 2018.

GAIVOTA, Daniel. Poética do deslocamento: nomadismo, diferença e narrativa da Escola. Rio de Janeiro: Nefi, 2017 (Coleção: Teses e Dissertações, 5).

GUEDES, Adrianne Ogêda; FERREIRA, Michelle Dantas. O professor de educação infantil, a arte e a educação estética: percursos de um grupo de pesquisa. In: Reunião Anual da ANPEd, 38, 2017, São Luís. Anais Eletrônicos... Disponível em:

http://38reuniao.anped.org.br/sites/default/files/resources/programacao/trabalho_38anped_201 7_GT07_689.pdf_Acesso em: 22 jan. 2017.

KOHAN, Walter Omar. Infância, estrangeiridade e ignorância - Ensaios de filosofia e educação. Belo Horizonte: Autêntica, 2007.

LARROSA, Jorge. Pedagogia profana. Danças, piruetas e mascaradas. Tradução Alfredo Veiga-Neto 4. ed. $3^{\text {a }}$ imp. Belo Horizonte: Autêntica, 2006.

LARROSA, Jorge. Experiência e alteridade em educação. Reflexão e Ação - Revista do Departamento de Educação e do Programa de Pós-graduação em Educação. v. 19, n. 2, 2011. doi: http://dx.doi.org/10.17058/rea.v19i2.2444 Disponível em: https://online.unisc.br/seer/index.php/reflex/article/view/2444/1898 Acesso em: 05 dez. 2016.

LARROSA, Jorge. Tremores: Escritos sobre experiência. Tradução Cristina Antunes, João Wanderley Geraldi. Belo Horizonte: Autêntica, 2016.

LOPONTE, Luciana Gruppelli. Arte e metáforas contemporâneas para pensar infância e educação. Revista Brasileira de Educação. Rio de Janeiro, v. 13, n. 37, p. 112-122, jan./abr. 2008. doi: https://doi.org/10.1590/S1413-24782008000100010 Disponível em: https://www.scielo.br/scielo.php?script=sci_arttext\&pid=S141324782008000100010\&lang=pt Acesso em: 06 jul. 2020.

MASSCHELEIN, Jan; SIMONS, Maarten. Em defesa da escola: uma questão pública. Tradução Cristina Antunes. 2. ed. Belo Horizonte: Autêntica, 2014.

PAGNI, Pedro Angelo. Experiência estética, formação humana e arte de viver: desafios filosóficos à educação escolar. São Paulo: Loyola, 2014.

PASSOS, Eduardo; KASTRUP, Virgínia; ESCÓSSIA, Liliana (Org.). Pistas do método da cartografia: pesquisa-intervenção e produção de subjetividade. Porto Alegre: Sulina, 2015.

PASSOS, Eduardo; KASTRUP, Virgínia; TEDESCO, Silvia (orgs.). Pistas do método da cartografia: a experiência da pesquisa e o plano comum. Porto Alegre: Sulina, 2016. 
RIBEIRO, Tiago; SOUZA, Rafael de; SAMPAIO, Carmen Sanches (orgs.). Conversas como metodologia de pesquisa: por que não? Rio de Janeiro: Ayvu, 2018.

RODRIGUES, Luiza Silva; ROBLE, Odilon José. Educação dos sentidos na contemporaneidade e suas implicações pedagógicas. Pro-Posições, Campinas, v. 26, n. 3, p. 205-224, set./dez, 2015. doi: http://dx.doi.org/10.1590/0103-7307201507810 Disponível em: https://www.scielo.br/pdf/pp/v26n3/0103-7307-pp-26-03-0205.pdf> Acesso em: 06 jul. 2020.

ROLNIK, Suely. Cartografia Sentimental: transformações contemporâneas do desejo. 2. ed. Porto Alegre: Sulina; Editora da UFRGS, 2014.

SKLIAR, Carlos. A escuta das diferenças. Porto Alegre: Mediação, 2019. 